\title{
Comparative analysis of Hungarian Matricaria recutita (L.) Rausch. populations
}

\author{
Sztefanov, A., Szabó, K. and Bernáth, J. \\ Szent István University, Faculty of Horticultural Sciences, Department of Medicinal and Aromatic Plants, \\ 1118 Budapest, Villányi str. 29, Hungary
}

\begin{abstract}
Summary: Matricaria recutita L. is a traditional medicinal plant in Hungary and its drug is known as „Hungaricum”, world-wide. Plant samples and seeds were collected from 12 different habitats of three significant geographical regions of Hungary in 2001. Morphological, production biological and chemical properties of samples were examined. In relation to the morphological characteristics, a negative correlation $(\mathrm{r}=-0.75$ ) could be observed between the average height of the plants (height of flowering shoots) and the $\mathrm{pH}$ value of the soil. According to the composition of the essential oil, the populations accumulating typically chamasulene (10-20\%), $\alpha$-bisabolol (30-50\%) or bisabolol-oxid $(30-50 \%)$ could be completely distinguished. Concerning the flavonoid composition the quantity of apigenin-7-glucoside was outstanding in the populations originating from the Great Hungarian Plain, it has reached the concentration of $1.8-2.8 \mathrm{mg} / \mathrm{g}$, while the samples collected in Transdanubia could be characterised by much lower level of apigenin-7-glucoside (around $1.5 \mathrm{mg} / \mathrm{g}$ ).
\end{abstract}

Key words: chamomile, Matricaria chamomilla, Chamomilla recutita, essential oil, chamasulene, $\alpha$-bisabolol, bisabolol-oxid, thin-layer chromatography, flavon-glycosides, apigenin

\section{Introduction}

Chamomile (Matricaria recutita L.) is a traditional medicinal plant in Hungary and its drug is known as „Hungaricum”, world-wide (Bernáth \& Németh, 2001). The excellent quality of the chamomile drug (Chamomillae flos) is due to the unique ecological conditions being present under different Hungarian wild habitats (Bernáth, 2000). Chamomile is in Hungary rather wide-spread. (Figure 1). However, it would be reasonable to characterise its regional occurrence by up to date methods, because there are some differences in plant habit, biomass production as well as in content and composition of active substances, as it was described earlier by Máthé \& Priszter (1979).

In the past decades the background information on the active compounds of chamomile, their biological activity and heritability has been changed completely. Nowadays the development of varieties (chemovarieties) accumulating one special type of active constituent is an important breeding objective and new active constituents have been taken into consideration. It was proved that the antiphlogistic and spasmolytic effects of chamomile are due to flavonoids along with sesquiterpenes as well. The most important flavonoid compound, flavone apigenin is present in plants as a bound form as apigenin- 7-O-glucoside and its acetylated derivatives (mono- and diacetates), which are localised in the white ligular florets only (Schilcher, 1987). In the case of Hungarian wild chamomile populations, the apigenin content has not been examined up to the present.

The chamomile anthodium and the essential oil are official drugs in almost every national pharmacopoeia, consequently the different chemotypes are investigated internationally. In the surrounding countries (Germany,

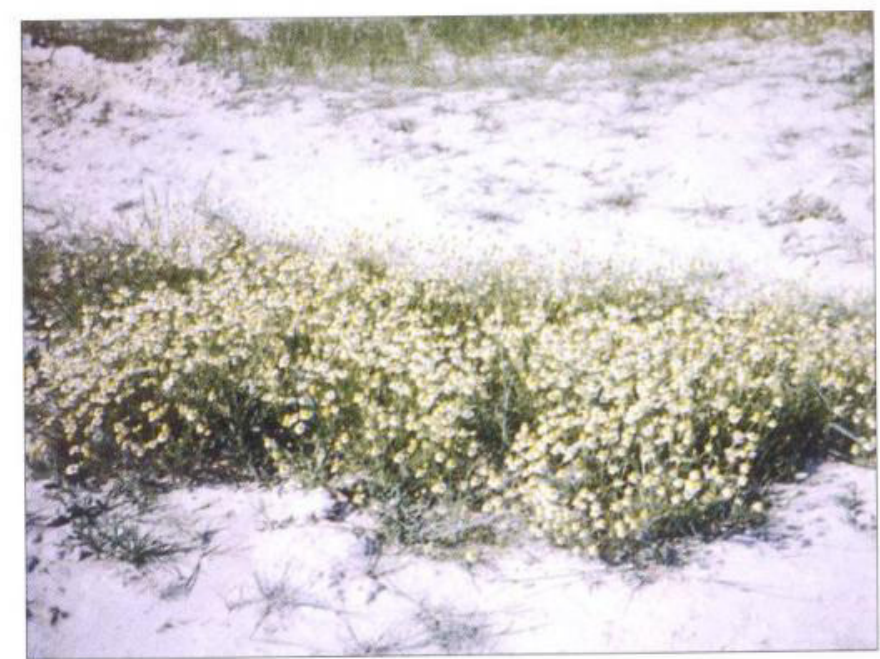

Figure 1 Matricaria chamomilla L. growing on alkali soil at the Danube-Tisza Mid Region (Felsốerek, 2001)

Austria, Slovakia, Poland and Yugoslavia) intensive breeding work was carried out on the subject (Massaud \& Franz, 1990, Gasic et al., 1991, Repcak et al., 1993, Repcak \& Oravec, 1993). The chamomile was among the first medicinal plant species for that the DUS directives and measurement methods has been worked out by UPOV (Anonym, 1995).

Realising the above-mentioned situation investigations have been started by us at SZI University, Faculty of Horticultural Sciences, Department of Medicinal and Aromatic Plants on the variability of the native, wild growing chamomile populations in order to select the most adequate taxa with high content of active compounds, which could be cultivated or used for breeding. 


\section{Material and method}

During May of 2001 plant samples and seeds were collected from 12 different habitats of three significant geographical region of Hungary: the northern part of the Great Hungarian Plain, Danube-Tisza Mid Region and Transdanubia (Figure 2). Morphological and production biological properties of the samples originating from different habitats were examined. The most important soil characteristics were also determined (Table I).

Morphological features (plant height, height of flowering level, length of internodes, diameter of flowers, diameter of the discus, intensity of green colour, pinnation) were evaluated taking into consideration the evaluation parameters of DUS in the case of 25 randomly selected specimens (Table 2). Minimum-, maximum-, average values and the coefficient of variance $(\mathrm{CV} \%)$ were statistically determined.

In the case of the active substances, essential oil content and composition as well as flavonoid composition were analysed. Dried samples were water-distilled in a Clevengerapparatus based on the standard method of $\mathrm{Ph} . \mathrm{Hg}$. VII. The essential oil content was calculated as a percentage of the dry

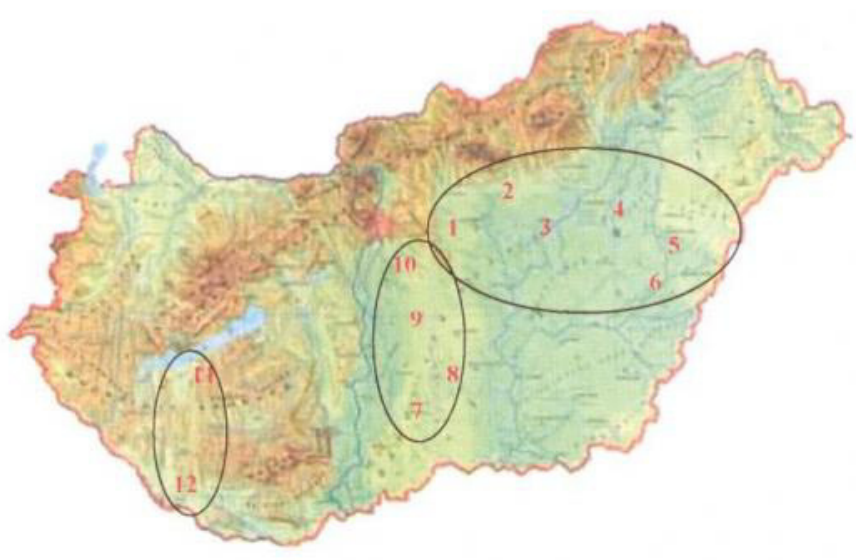

Figure 2 Chamomile collecting areas in 2001 (Name of the habitat is given in Table 1)

mass. The main chemical compounds of the essential oil were determined by GC method in a capillary gas chromatograph (Shimadzu GC-B14 with Shimadzu Class VP Chromatography Data System 4.2) equipped with FID. An SE-30 (30 m x $0.25 \mathrm{~mm})$ i.d. column was used (film thickness $0.25 \mathrm{im}$ ). The injector and detector temperatures

Table I Results of the soil-analysis (SZIU, Faculty of Food Science, Central Laboratory, 2001)

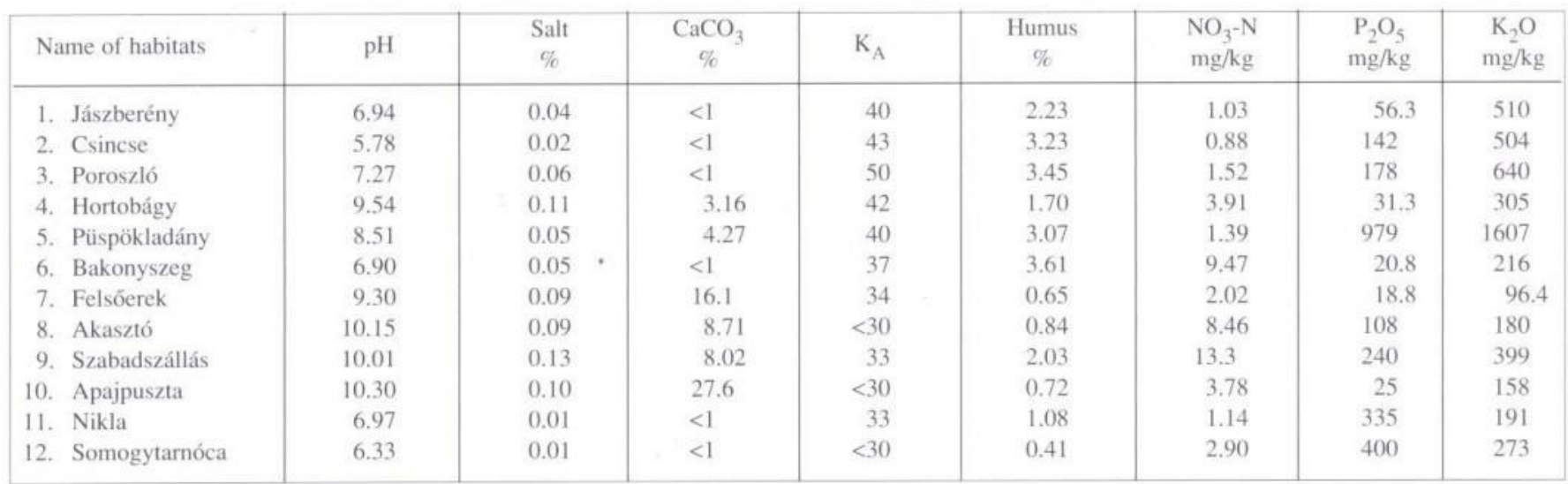

Table 2 Values measured by the National Institute for Agricultural Quality Control in the case of a Hungarian chamomile cultivar „.Soroksári 40” according to the DUS evaluation system (Anonym, 1995)

\begin{tabular}{|l|c|}
\hline Characteristics & Degree of expression \\
\hline Ploidity & diploid \\
Plant: height (in full flowering) & high \\
Plant: height of the flowering level & medium \\
Plant: density of the leaves (in budding stage) & slight or not at all \\
Stem:antocyanide colouration (beginning of flow.) & dark \\
Leaf: intensity of green colour (in budding stage) & medium \\
Leaf: pinnation (leaves in the middle of the stem) & medium \\
Flower: diameter with ligular flowers & medium \\
Flower: diameter of discus & low-medium \\
Flower: essential oil content & low \\
Essential oil: chamasulene content & very low-low \\
Essential oil: a-bisabolol content & late \\
Date of the beginning of flowering & late \\
Date of full flowering & 4 \\
\hline
\end{tabular}


were $220^{\circ} \mathrm{C}$ and $250^{\circ} \mathrm{C}$, respectively. Column temperature program: $160^{\circ} \mathrm{C}(3 \mathrm{~min}),. 160-240^{\circ} \mathrm{C}\left(6^{\circ} \mathrm{C} / \mathrm{min}\right), 240^{\circ} \mathrm{C}$ (15 min.) The carrier gas was nitrogen, $1 \mathrm{ml} / \mathrm{min}$ at the starting temperature, 1 il of essential oil of each sample was injected. The identification of the compounds was performed by comparison of their retention times with those of pure substances, by peak enrichment with standards. The relative percentage of the oil constituents was calculated based on the GC peak areas, as a percentage of the total area (Ph.Hg.VII., 1986).

The flavonoid composition was analysed by thin-layer chromatography (Wagner \& Bladt, 1996). The powdered drug was extracted with methanol on a water bath and then filtered. Reference compounds were rutin ( $\mathrm{Rf} 0.3$ ), chlorogenic acid ( $\mathrm{Rf} \sim 0.45)$, hyperoside $(\mathrm{Rf} \sim 0.55)$, (isoquercitrin ( $\mathrm{Rf} 0.6$ ), quercitrin ( $\mathrm{Rf} \sim 0.7$ ) and apigenin (Rf 0.8). As adsorbent Kieselgel $60 \mathrm{~F}_{254}$-precoated TLC plates (Merck), as solvent system ethyl acetate-formic acidwater $(8: 1: 1 \mathrm{~V} / \mathrm{V})$ were used. Constituents were detected in UV-254 nm, quantities were determined with TLC scanner.

\section{Results and discussion}

Examining the morphological characteristics, a negative correlation $(\mathrm{r}=-0.75)$ could be observed between the average height of the plants and the $\mathrm{pH}$ value of the soil of the habitat (Figure 3). Where the chemical reaction of the soil was about neutral ( $\mathrm{pH}=6-7$ ), the highest flowering shoots were measured (over $30 \mathrm{cms}$ ), while in the case of sodic, alkali soils $(\mathrm{pH}=9-10)$ in many cases the height of the plants has not reached the $20 \mathrm{cms}$, either.

The maximum of plant height $41.20 \mathrm{cms}$ in average $(\mathrm{CV} \%=6.39 \%)$ were measured in Transdanubia, at Nikla $(\mathrm{pH}=6.97)$ and $39.12 \mathrm{cms}(\mathrm{CV} \%=6.11 \%)$ in the northern part of the Great Hungarian Plain, at Csincse $(\mathrm{pH}=5.78)$. The shortest shoots were measured in the Danube-Tisza Mid Region, at Felsốerek $(\mathrm{pH}=9.30)$, with mean value of 18.72 $\mathrm{cms}(\mathrm{CV} \%=9.00)$ and in the Great Hungarian Plain, at Hortobágy ( $\mathrm{pH}=9.54)$ with $19,76 \mathrm{cms}(\mathrm{CV} \%=17.43)$ average plant height (Table 3). This is in harmony with previous observations described in the literature (Máthé \&

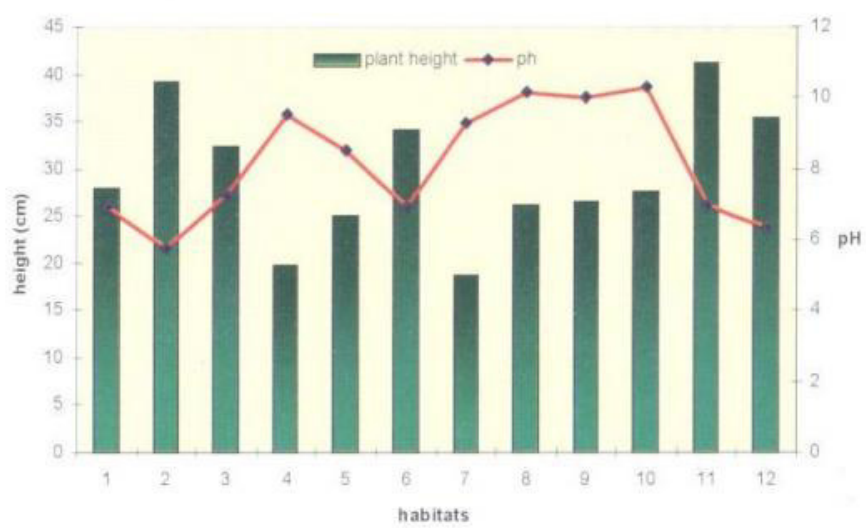

Figure 3 Correlation between plant height and the $\mathrm{pH}$ value of the soil at different habitats (Name of the habitat is given in Table 1)

Priszter, 1979) concerning the phenomenon that the highest plants occur in Transdanubia.

Average diameter of anthodia was outstanding $2.08 \mathrm{cms}$ $(\mathrm{CV} \%=7.57 \%)$ in Szabadszállás belonging to the Danube-Tisza Mid Region, as well as in Transdanubia in Nikla where $1.90 \mathrm{cms}(\mathrm{CV}=10.96 \%)$ values were measured (Table 3). Similarly, the anthodia were rather large at Somogytarnóca showing $2.07 \mathrm{cms}(\mathrm{CV} \%=9.64 \%)$ values. The anthodium size is a bit smaller than defined in the standard Hungarian cultivars 'Soroksári 40' (2.5-2.7 cms) and c.v. 'Budakalászi (2.6-2.8 cms) by the National Institute for Agricultural Quality Control (2001).

Concerning the chemical composition the quantity of the essential oil exceeded $0.9 \%$ in three populations, two originating from the Danube-Tisza Mid Region (Akasztó $1.3 \%$, Felsốerek 1.0\%) and one from Transdanubia (Somogytarnóca 1.3\%). In the case of the other populations these values were below $0.9 \%$ (Table 4 ). According to the data of the Hungarian National Institute for Agricultural Quality Control (Anonym, 2001) the average essential oil content of c.v. 'Soroksári 40 ' is $0.8 \%$, c.v. 'Budakalászi 2' is $0.6-0.7 \%$. Our results are in harmony with these data, and in some cases (e.g. Akasztó, Felsốerek, Somogytarnóca) the content of the essential oil proved to be higher, than the average values of the two Hungarian cultivars.

Table 3 Results of the morphological examinations (Name of the habitat is given in Table 1)

\begin{tabular}{|c|c|c|c|c|c|c|c|}
\hline $\begin{array}{l}\text { Num. of } \\
\text { the habitats }\end{array}$ & $\begin{array}{l}\text { Plant height } \\
(\mathrm{cm})\end{array}$ & $\begin{array}{l}\text { Flow. level } \\
\qquad(\mathrm{cm})\end{array}$ & $\begin{array}{l}\text { Internods } \\
(\mathrm{cm})\end{array}$ & $\begin{array}{l}\text { Diameter of flowers } \\
\qquad(\mathrm{cm})\end{array}$ & $\begin{array}{l}\text { Diameter of discus } \\
\qquad(\mathrm{cm})\end{array}$ & $\begin{array}{c}\text { Green colour } \\
(1-3)\end{array}$ & $\begin{array}{l}\text { Pinnation } \\
\quad(1-3)\end{array}$ \\
\hline 1 & 27.88 & 5.86 & 1.68 & 1.43 & 0.66 & 1.64 & 2.44 \\
\hline 2 & 39.12 & 5.88 & 2.40 & 1.54 & 0.72 & 1.52 & 2.28 \\
\hline 3 & 32.24 & 6.28 & 2.26 & 1.78 & 0.81 & 1.16 & 2.24 \\
\hline 4 & 19.76 & 4.02 & 1.62 & 1.58 & 0.64 & 1.40 & 1.56 \\
\hline 5 & 24.96 & 4.24 & 2.66 & 1.63 & 0.80 & 1.68 & 2.24 \\
\hline 6 & 34.16 & 5.24 & 2.76 & 1.49 & 0.69 & 1.72 & 2.20 \\
\hline 7 & 18.72 & 4.04 & 1.70 & 1.85 & 0.86 & 2.60 & 1.92 \\
\hline 8 & 26.12 & 4.74 & 1.96 & 1.63 & 0.80 & 1.72 & 1.88 \\
\hline 9 & 26.56 & 4.76 & 1.46 & 2.08 & 0.86 & 2.04 & 2,48 \\
\hline 10 & 27.52 & 4.44 & 1.64 & 1.78 & 0.84 & 1.36 & 1.88 \\
\hline 11 & 41.20 & 5.02 & 1.74 & 1.90 & 0.78 & 2.12 & 2.68 \\
\hline 12 & 35.40 & 4.24 & 1.54 & 2.07 & 0.80 & 1.20 & 2.50 \\
\hline
\end{tabular}


Table 4 Essential oil content and composition (\%) (Name of the habitat is given in Table 1)

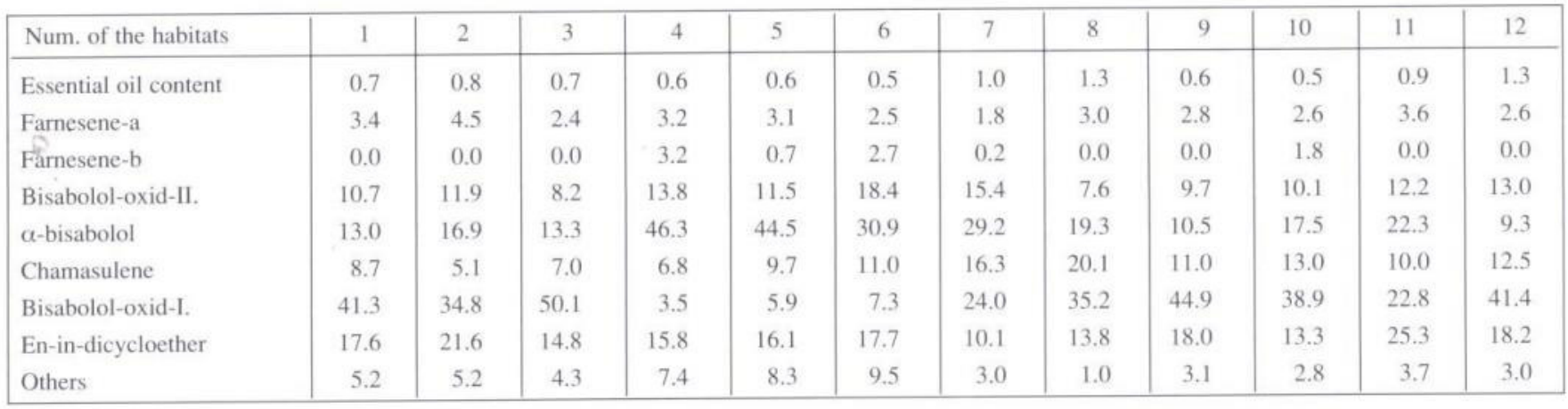

According to the composition of the essential oil, the populations accumulating typically chamasulene $(10-20 \%)$, $\alpha$-bisabolol (30-50\%) or bisabolol-oxid (30-50\%) could be completely distinguished (Table 4). Drug samples originating from the northern part of Great Hungarian Plain and Transdanubia, contain mainly bisabolol-oxid (Poroszló, $50.1 \%$ ) and $\alpha$-bisabolol (Hortobágy, 46.3\%), while samples collected in Danube-Tisza Mid Region could be characterised by higher accumulation of chamasulene (Akasztó, 20.1\%) (Figure 4). According to Máthé \& Priszter (1979) samples collected from the most continental areas of the country (the north-eastern part of the Great Hungarian Plain) could be characterised by lower chamasulene values, while samples collected from less continental regions with neutral or slightly acidic soil could be characterised by higher chamasulene values. This study is in accordance with our results.

Comparing the flavonoid composition of the samples, the quantity of apigenin-7-glucoside proved to be outstanding in the populations originating from the Great Hungarian Plain, its value has reached the $1.8-2.8 \mathrm{mg} / \mathrm{g}$ concentration. The highest apigenin-7-glucoside content was measured in Bakonyszeg, the most eastern part of the Great Hungarian Plain. Drug samples collected in Transdanubia could be characterised by lower level of apigenin-7-glucoside, their accumulation values were around $2 \mathrm{mg} / \mathrm{g}$ (Figure 5). Interesting, that in the case of the habitat Felsôerek, the lowest apigenin-7-glucoside content

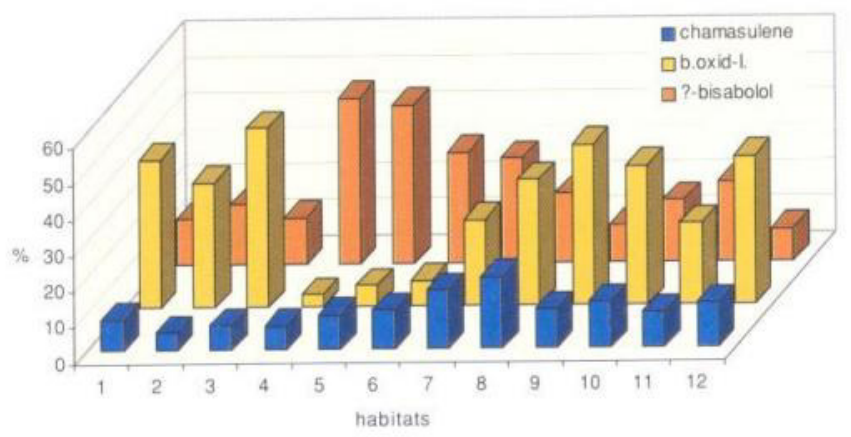

Figure 4 Correlation between plant height and the $\mathrm{pH}$ value of the soil at different habitats (Name of the habitat is given in Table 1) was measured $(1.3 \mathrm{mg} / \mathrm{g})$, where the collection was carried out a bit late, when the anthodia were in the stage of deflorescence and the white ligular flowers were already fading away. In the work of Máthé \& Priszter (1979) only German materials were examined from the point of view of apigenin flavon glycosides, $1.27-5.26 \mathrm{mg} / \mathrm{g}$ was measured in the anthodia. The published data on apigenin glucoside content in chamomile are showing great variations. Dölle \& Carle (1985) registered $3.0-6.6 \mathrm{mg} / \mathrm{g}$ of apigenin-7glucoside. According to Repcak \& Oravec (1993) the tetraploid variety of chamomile ' $N L 90^{\prime}$ ' accumulates about $2.2-5.2 \mathrm{mg} / \mathrm{g}$ apigenin-7-glucoside in anthodia.

Summarising our results, it could be stated, that the 12 wild growing Hungarian chamomile population could be completely distinguished from the point of view of morphological characteristics and chemical composition, either. Some of the examined populations characterised by advantageous features (large diameter of the anthodium, high accumulation level of the essential oil, apigenin flavonglycoside, etc.) could be promising in the future. Populations described by high accumulation levels of all important essential oil constituents together as well as separately, also deserve attention.

In order to establish, in what extent the morphological and production biological characteristics of wilde-growing chamomile are determined genetically, or by environmental factors, further experiments are required either under the same ecological conditions or in phytotron chambers.

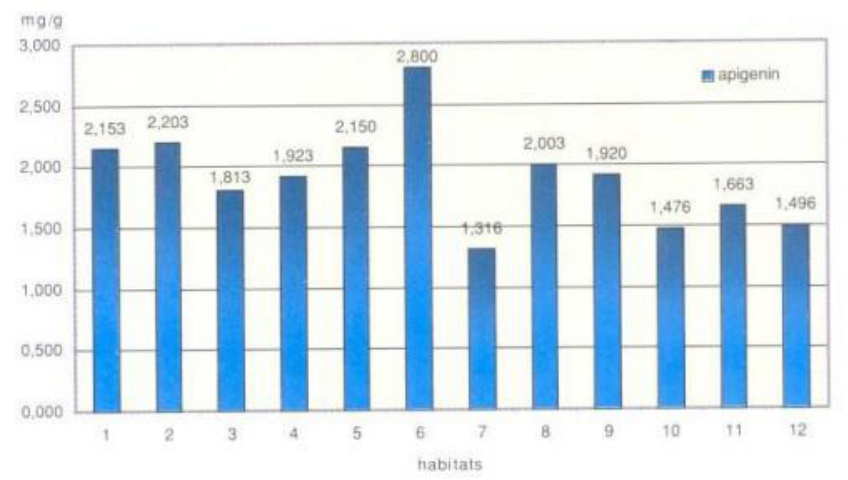

Figure 5 The quantity of apigenin at the different habitats $(\mathrm{mg} / \mathrm{g})$ (Name of the habitat is given in Table 1) 


\section{References}

Anonym (1995): International Union for the Protection of New Plant Varieties (UPOV), Guideline for Conduct of Tests for Distinctness, Uniformity and Stability, Genf

Anonym (2001): National Institute for Agricultural Quality Control, OMMI, Medicinal Plant Varieties of Hungary, 32-33.

Bernáth J. (editor) (2000): Gyógy- és Aromanövények, Mezốgazda, Budapest, p. 413-421.

Bernáth J. \& Németh É. (2001): Ecological diversity of Hungarian medicinal and aromatic plant flora and its regional consequences. Int. J. Hort. Sci., 7. (2):

Dölle, B. \& Carle, R. (1985): Flavonoid Bestimmung in Kamillen Extractpräparaten. Dtsch. Apoth.-Ztg.

Gasic, O., Lukic, V. \& Adamovic, D. (1991): The influence of sowing and harvest time on the essential oils of Chamomilla recutita (L.) Rausch., J. Ess. Oil Res, 3: 295-302

Massaud, H. \& Franz, Ch. (1990): Quantitative genetical aspects of Chamomilla recutita (L.) Rauschert, J. Ess. Oil Res. 2: 15-20.
Máthé I.. \& Priszter Sz. (1979): A kamilla, Matricaria chamomilla L., Magyarország kultúrflórája, Edited by: Máthé I., Akadémiai kiadó, Budapest

MSZ 6388-84 (1984): Kamilla virágzat drog

Ph.Hg.VII. (1986): Hungarian Pharmacopoea, VII., Volume I., Medicina, Budapest

Repèak, M., Cernaj, P. \& Martonfi, P. (1993): The essential oil content and composition in diploid and tetraploid Chamomilla recutita during the ontogenesis of anthodia, J. Ess. Oil Res. 5: 297-300.

Repčak, M. \& Oravec, V. (1993): Apigenin glucosides in tetraploid bisabolol variety of camomile. Acta Horticulturae, 330: 213-218.

Schilcher, H. (1987): Die Kamille. Wiss. Verl., Stuttgart

Wagner, H. \& Bladt, S. (1996): Plant Drug Analysis. A Thin Layer Chromatography Atlas. Springer, Berlin, Tokyo, 203-228. 